\title{
IMPROVED OSTEOGENIC VECTOR FOR NON-VIRAL GENE THERAPY
}

\author{
A.R.A. Hacobian*, K. Posa-Markaryan, S. Sperger, M. Stainer, D. Hercher, G. A. Feichtinger, C.M.A.P. Schuh
} and H. Redl

Ludwig Boltzmann Institute for Experimental and Clinical Traumatology/AUVA Research Center, The Austrian Cluster for Tissue Regeneration, European Institute of Excellence on Tissue Engineering and Regenerative Medicine Research (Expertissues EEIG), Vienna, Austria.

\begin{abstract}
Therapeutic compensation of deficient bone regeneration is a challenging task and a topic of on-going search for novel treatment strategies. One promising approach for improvement involves non-viral gene delivery using the bone morphogenetic protein-2 (BMP-2) gene to provide transient, local and sustained expression of the growth factor. However, since efficiency of non-viral gene delivery is low, this study focused on the improvement of a BMP2 gene expression system, aiming for compensation of poor transfection efficiency. First, the native BMP-2 gene sequence was modified by codon optimisation and altered by inserting a highly truncated artificial intron (96 bp). Transfection of multiple cell lines and rat adipose-derived mesenchymal stem cells with plasmids harbouring the improved BMP-2 sequence led to a several fold increased expression rate and subsequent osteogenic differentiation. Additionally, comparing expression kinetics of elongation factor 1 alpha (EF1 $\alpha$ ) promoter with a state of the art CMV promoter revealed significantly higher BMP-2 expression when under the influence of the EF1 $\alpha$ promoter. Results obtained by quantification of bone markers as well as osteogenic assays showed reduced sensitivity to promoter silencing effects of the EF1 $\alpha$ promoter in rat adiposederived mesenchymal stem cells. Finally, screening of several protein secretion signals using either luciferase or BMP-2 as reporter protein revealed no superior candidates for potential replacement of the native BMP-2 secretion signal. Taken together, by enhancing the exogenous BMP-2 expression system, low transfection efficiencies in therapeutic applications can be compensated, making safe non-viral systems even more suitable for tissue regeneration approaches.
\end{abstract}

Keywords: Bone morphogenetic protein, gene therapy, osteogenic differentiation, bone regeneration, codon optimisation, intron, non-viral, secretion signal.

*Address for correspondence:

Ara Hacobian,

Ludwig Boltzmann Institute for Experimental and Clinical Traumatology,

Donaueschingenstrasse 13, A-1200 Vienna, Austria,

Telephone Number: +43 (0) 59393-41961, E-Mail: ara.hacobian@trauma.lbg.ac.at

\section{Introduction}

One focus within the field of regenerative medicine is the reconstruction of bone defects or compensation of deficient regeneration. Several studies have investigated the practicability of applying growth factors, either in form of recombinant proteins or by means of gene therapy encoding an exogenous gene on a plasmid (Feichtinger et al., 2014; Kempen et al., 2010; Koh et al., 2008; Sood et al., 2012). Recombinant proteins used in therapeutic approaches generally show a short half-life at the target site (Alt et al., 2009; Sandhu, 2004). Therefore, delivery of up to $\mathrm{mg}$ dosages at once are required to provide a sufficient stimulus. As a result, these supraphysiological local dosages lead to increased occurrence of protein diffusion and side effects (Carragee et al., 2011; Glassman et al., 2011; Shimer et al., 2009). As a promising alternative, gene therapy allows local and sustained release of growth factors. Due to this moderate and constant release, it is more suitable for regenerative processes compared to administration of high protein doses, (Bleiziffer et al., 2007; Southwood et al., 2004). Therefore, the use of gene therapy in order to stimulate bone formation by introducing deoxyribonucleic acid (DNA) vectors encoding for therapeutic genes is very promising. However, compared to viral gene delivery methods, non-viral gene therapy shows generally low gene transfer efficiency, especially in vivo. Nevertheless, non-viral approaches do not trigger the host's immune responses that much, due to lack of viral protein components and also have a very rare frequency of inserting into host genome (Martin et al., 1999). Furthermore, there is no size limitation concerning coding sequence and production is cost-efficient, safe and easy. Taking these factors into account, non-viral delivery methods are considered the most suitable candidates for clinical translation of tissue regenerative gene therapy. Therefore, instead of making viral gene transfer safer, currently a large number of on-going attempts are focussing on the enhancement of non-viral approaches (Bleiziffer et al., 2007; Glover et al., 2005). There is still plenty of room for improvement of the presently available non-viral vectors, regarding expression rate and duration (Al-Dosari and Gao, 2009; Kay, 2011; Mingozzi and High, 2011; Wang et al., 2013). Methods for improvement of bone morphogenetic protein 2 (BMP-2) expression systems are introduced in this work in order to promote further development of non-viral gene delivery approaches making safe non-viral systems even more applicable (Fig. 1).

Due to the ability to induce bone formation in vitro and in vivo (Celeste et al., 1990; Reddi, 1998; Wozney and Rosen, 1998), BMP-2 represents a standard growth 


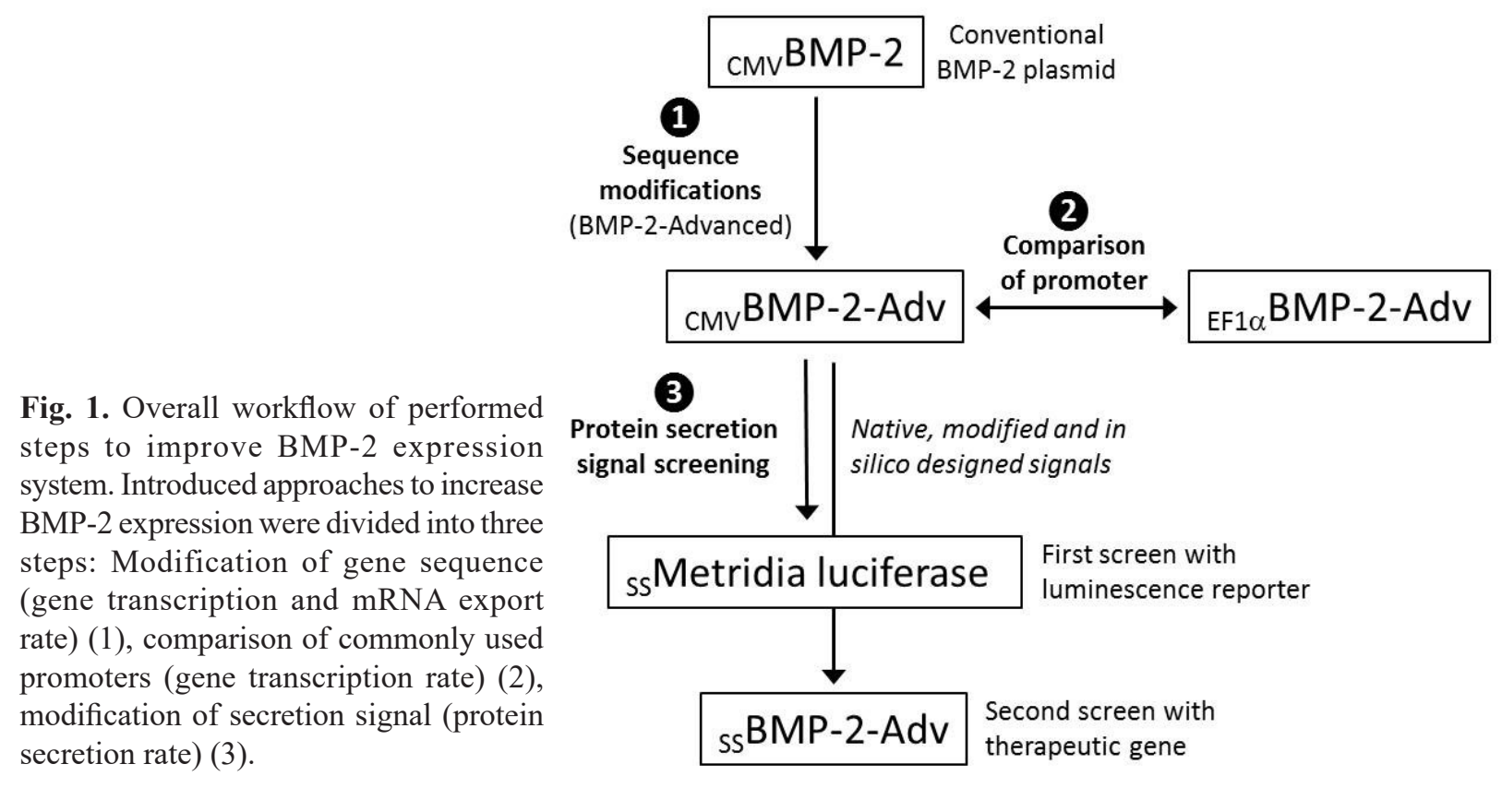

factor candidate for osteogenic gene therapy (Bonadio et al., 1999; Einhorn, 2003; Johnson and Urist, 2000; Loozen et al., 2015; Osawa et al., 2009; Tepper and Mehrara, 2002). As such, this work focuses on the improvement of a BMP-2 gene expression system in different cell lines and rat adipose-derived mesenchymal stem cells in order to compensate for low non-viral gene transfer levels in bone regeneration. Generally, introduced approaches to increase BMP-2 expression were divided into three steps: modification of gene sequence, comparison of commonly used promoters, and screening for efficient protein secretion signals (Fig. 1). For sequence modification, codon optimisation and insertion of an artificial intron were applied. In general, different codons are preferentially used in different organisms, which is dependent on the tRNA concentration inside the cell. Codon usage plays an important role in the regulation of protein biosynthesis. Therefore, rarely used codons can slow down translation, whereas frequently used codons can accelerate translation (Cai et al., 2013; Fath et al., 2011). Also, insertion of introns is known to enhance transcription rates and messenger ribonucleic acid (mRNA) stability and export into the cytosol (Moabbi et al., 2012; Rose, 2008). The expression level of intron-less genes is often 10 to 100 times lower than the intron-containing counterpart (Le Hir et al., 2003).

Here, application of both strategies, codon usage within the BMP-2 gene to codons commonly used by human and murine cells and insertion of an artificial highly minimised intron, showed several fold increase in BMP-2 expression and osteogenic differentiation of transfected cell lines and rat adipose-derived stem cells compared to cells transfected with native BMP-2 gene. As an additional step to improve the BMP-2 gene expression system, strength and persistency of regulatory elements were investigated. Comparison of cytomegalovirus (CMV) promoter activity with the eukaryotic elongation factor 1 alpha $(E F 1 \alpha)$ promoter indicates limitations in efficiency of BMP-2 expression induced by the well-established CMV promoter in rat adipose-derived mesenchymal stem cells.

Finally, protein secretion sequences were another focus of investigation. It has been previously demonstrated that the expression and final yield of recombinant proteins do not necessarily correlate with their mRNA levels (Barnes et al., 2004; Knappskog et al., 2007). The secretion of proteins can be a limiting step if the native protein secretion signal is weak. The different potencies of secretion signals to drive protein secretion can be related to their amino acid composition (Futatsumori-Sugai and Tsumoto, 2010; Klatt and Konthur, 2012; Knappskog et al., 2007; Kober et al., 2013; Wen et al., 2011; Zhang et al., 2005). Based on this, the present study was expanded by the addition of screening and modification of protein secretion signals in order to identify signal peptide candidates with beneficial activity for subsequent exchange of the native BMP-2 protein secretion sequence. Therefore, secretion sequence screenings were performed by transfection of cell lines with plasmid encoding for a luciferase reporter protein (Metridia luciferase) with its secretion signals selectively replaced with foreign signals. As second step, the Metridia luciferase reporter was exchanged with therapeutic BMP-2 gene and most potent signals were evaluated either indirectly by differentiation assays or by direct quantification of BMP-2 secretion.

\section{Materials and Methods}

\section{Optimisation of BMP-2 gene sequence}

Human BMP-2 gene sequence (Gene ID: 650) was modified by codon optimisation using the GeneOptimizer ${ }^{\circledR}$ expert algorithm. Additionally, a highly truncated artificial intron ( 96 base pairs) was inserted into the open reading frame leading to an improved BMP-2 cassette (BMP-2Advanced) with highly enhanced gene expression activity. Additionally, a second vector was constructed harbouring 
Table 1: Overview of vectors used in this study.

\begin{tabular}{|l|l|l|l|}
\hline Original name & Description & Abbreviation & Backbone \\
\hline pVax1-BMP-2 & Conventional BMP-2 gene under CMV promoter & ${ }_{\text {смV BMP-2 }}$ & pVax1 \\
\hline pVax1-BMP-2-Advanced & Optimised BMP-2 gene under CMV promoter & ${ }_{\text {СMV }}$ BMP-2-Adv & pVax1 \\
\hline pEF1 $\alpha$-BMP-2-Advanced & Optimised BMP-2 gene under EF1 $\alpha$ promoter & ${ }_{\text {EF } 1 \alpha}$ BMP-2-Adv & pVax1 \\
\hline
\end{tabular}

Table 2: List of the amino acid sequences of the secretion signal peptides used in this study, including their protein and species of origin.

\begin{tabular}{|c|c|c|c|}
\hline Name & Amino acid sequence & Origin (protein) & Origin (species) \\
\hline Blank & M & - & - \\
\hline hBMP2 & MVAGTRCLLALLLPQVLLGGAAG & Bone morphogenetic protein 2 & Homo sapiens \\
\hline mBMP2 & MVAGTRCLLALLLPQVLLG & Bone morphogenetic protein 2 & Mus musculus \\
\hline BMP7 & MGVRSLRAAAPHSFVALWAPLFLLRSALA & Bone morphogenetic protein 7 & Mus musculus \\
\hline BMP6 & MPGLGRRAQWLCWWWGLLCS & Bone morphogenetic protein 6 & Mus musculus \\
\hline Nog & MERCPSLGVTLYALVVVLGLRAAPAGG & Noggin & Mus musculus \\
\hline Cho & MPSLPAPPAPRLLLGLLLLGSRPASG & Chordin & Mus musculus \\
\hline Gre & MNRTAYTVGALLLLLGTLLPTAEG & Gremlin-1 & Mus musculus \\
\hline Azu & MTRLTVLALLAGLLASSRA & Azurocidin-1 & Homo sapiens \\
\hline Alb & MKWVTFLLLLFVSGSAFS & Albumin & Mus musculus \\
\hline $\mathrm{mB} 2 \mathrm{a}$ & MVAGTRCLLALLLPQVLLPPASA & Bone morphogenetic protein 2 (modified) & Homo sapiens \\
\hline $\mathrm{mB} 2 \mathrm{P}$ & MVAGTRCLLVLLLPQVLLG & Bone morphogenetic protein 2 (modified) & Mus musculus \\
\hline TGF & MPPSGLRLLPLLLPLPWLLVLTPGRPAAG & Transforming growth factor beta & Mus musculus \\
\hline $\operatorname{Trp} 1$ & MNPLLILTFVAAALA & Trypsinogen 1 & Mus musculus \\
\hline $\operatorname{Trp} 2$ & MNLLLILTFVAAAVA & Trypsinogen 2 & Mus musculus \\
\hline Smo & MLPARCARLLTPHLLLVLVQLSPARG & $\begin{array}{l}\text { SPARC-related modular calcium-binding protein } \\
1 \text { (SMOC1) }\end{array}$ & Mus musculus \\
\hline Osc & MRTLSLLTLLALAALCLSDLTDA & Osteocalcin & Mus musculus \\
\hline Osp & MRIAVICFCLLGIASA & Osteopontin & Mus musculus \\
\hline Amy & MLPGLALLLLAAWTARA & Amyloid beta A4 protein & Homo sapiens \\
\hline hVEGF & MNFLLSWVHWSLALLLYLHHAKWSQA & Vascular Endothelial Growth Factor A & Homo sapiens \\
\hline HGF & MWVTKLLPALLLQHVLLHLLLLPIAIPYAEG & Hepatocyte growth factor & Mus musculus \\
\hline Gau & MGVKVLFALICIAVAEA & Gaussia luciferase & Gaussia princeps \\
\hline Met & MDIKVVFTLVFSALVQA & Metridia luciferase & Metridia longa \\
\hline hGDNF & MKLWDVVAVCLVLLHTASA & Glial cell line-derived neurotrophic factor (GDNF) & Homo sapiens \\
\hline hBDNF & MTILFLTMVISYFGCMKA & Brain-derived neurotrophic factor (BDNF) & Homo sapiens \\
\hline ChoTXN & MVKIIFVFFIFLSSFSYA & Cholera enterotoxin A subunit & Vibrio cholerae \\
\hline hIFNa2 & MALTFALLVALLVLSCKSSSVG & Interferon alpha 2 & Homo sapiens \\
\hline vIL10 & MERRLVVTLQCLVLLYLAPECGG & BCRF1 protein & Human herpes virus 4 \\
\hline $\mathrm{Z}$ & MERRLLLLLLLLLLGPASA & - & Artificial \\
\hline $\mathrm{Z} 2$ & MERRLLLLLLLLLLGPLLLLLLLLLLGPAS & - & Artificial \\
\hline Z3 I & MERRRRRRRRRLLLLLLLLLGPASA & - & Artificial \\
\hline Z 3 II & MERRLLLLGLLLLLLGLLLLLLLLLLGPASA & - & Artificial \\
\hline Z4R & MERRRRLLFSFSCCCWDQPLP & - & Artificial \\
\hline Gau-L2 & MGVKVLFALLICIAVAEA & Gaussia luciferase & Gaussia princeps \\
\hline Gau-L4 & MGVKVLFALLLLICIAVAEA & Gaussia luciferase & Gaussia princeps \\
\hline Gau-L6 & MGVKVLFALLLLLLICIAVAEA & Gaussia luciferase & Gaussia princeps \\
\hline Gau-L8 & MGVKVLFALLLLLLLLICIAVAEA & Gaussia luciferase & Gaussia princeps \\
\hline Gau-2L & MGVKVLLFALICIAVAEA & Gaussia luciferase & Gaussia princeps \\
\hline Gau-4L & MGVKVLLLLFALICIAVAEA & Gaussia luciferase & Gaussia princeps \\
\hline mBMP2-L6 & MVAGTRCLLALLLLLLPQVLLGGAAG & Bone morphogenetic protein 2 (modified) & Homo sapiens \\
\hline mBMP2-L8 & MVAGTRCLLALLLLLLLLPQVLLGGAAG & Bone morphogenetic protein 2 (modified) & Homo sapiens \\
\hline MRL10 & MRLLLLLLLLLLGAAG & Bone morphogenetic protein 2 (modified) & Homo sapiens \\
\hline MRPL10 & MRPLLLLLLLLLLGAAG & Bone morphogenetic protein 2 (modified) & Homo sapiens \\
\hline MRRB2 & MRRMVAGTRCLLALLLPQVLLGGAAG & Bone morphogenetic protein 2 (modified) & Homo sapiens \\
\hline
\end{tabular}

the same BMP-2-Advanced cassette under the influence of an $\mathrm{EF} 1 \alpha$ promoter instead a CMV promoter in order to test variations in promoter expression kinetics in different cell types (Table 1).

\section{Secretion signal reporter vector construction}

Native secretion signal of Metridia luciferase gene from pMetLuc2-Control vector (Clontech, USA) was removed by polymerase chain reaction (PCR) amplification and NheI/HindIII restriction sites were introduced for 
subsequent insertion of oligonucleotides coding for particular protein secretion signals (Table 2). For the BMP2 vector, Metridia luciferase reporter was exchanged with advanced BMP-2 gene lacking its native protein secretion signal.

\section{Cell culture and reagents}

C2C12 mouse muscle myoblast precursor cell line (DSMZ, Germany, \#ACC565) was cultured in Dulbecco's Modified Eagles Medium (DMEM, Sigma Aldrich, USA) high glucose (4.5 g/L glucose), supplemented with $2 \mathrm{mM}$ L-glutamine (Sigma Aldrich, USA) and $5 \%$ foetal calf serum (FCS, Sigma Aldrich, USA). C3H/10T1/2 (ATCC ${ }^{\circledR}$ CCL-226 ${ }^{\mathrm{TM}}$, USA) mouse embryonal cells and chinese hamster ovary (CHO) cell line (ATCC ${ }^{\circledR}$ CCL-61 ${ }^{\mathrm{TM}}$, USA) were cultivated under same conditions except with $10 \%$ foetal calf serum.

\section{Isolation and cultivation of rat adipose-derived mesenchymal stem cells}

Epididymal fat pads of male rats (Sprague-Dawley, Charles River, Germany) were minced and incubated in $2 \%$ collagenase (Biochrom, Germany). Digestion was stopped by addition of culture medium (PAA, Austria) containing $10 \% \mathrm{FCS}$ and tissue remnants were filtered through $100 \mu \mathrm{m}$ cell strainers (BD Falcon, Germany), followed by centrifugation (seven minutes at $400 \times g$ ). The pellet containing pre-adipocytes, rat adipose-derived mesenchymal stem cells (rADSC) and stromal cells was washed with phosphate buffered saline (PBS) (PAA, Austria) and centrifuged at $400 \times g$. The resulting rADSCs isolated from adipose tissue were seeded on T75 cell culture flasks (PAA, Austria) for expansion. After isolation, rADSCs were cultivated using standard cell culture conditions $\left(37^{\circ} \mathrm{C}, 5 \% \mathrm{CO}_{2}\right)$ in DMEM (high glucose, PAA, Austria) supplemented with $10 \%$ FCS (PAA, Austria), $200 \mu \mathrm{M}$ L-glutamine and $1 \%$ antibiotics (PAA, Austria). For expansion, cells were cultivated in cell culture flasks (PAA, Austria) with an initial seeding density of $3 \times 10^{3}$ cells $/ \mathrm{cm}^{2}$. At a confluence of $80-90 \%$, cells were split with Accutase ${ }^{\mathrm{TM}}$ (PAA, Austria). Final verification was performed with rADSCs at passage number two by flow cytometry using haematopoietic markers (CD14, CD34, CD45) and mesenchymal markers (CD73, CD90 CD105) (data provided in the supplementary material). Isolated rADSCs were derived from five separate donors pooled together. All cell transfections were conducted at passage number three.

\section{Cell transfection}

Cells were seeded into 24 -well plates at a cell density of $0.25 \times 10^{5} / \mathrm{cm}^{2} 24 \mathrm{~h}$ before transfection. The next day, the plasmid was incubated with transfection reagent in serum-free medium for $15 \mathrm{~min}$. Target cells in growth medium containing $5 \%$ FCS were transfected with $1 \mu \mathrm{g}$ of indicated plasmid using $3 \mu \mathrm{L}$ of Peqfect (Peqlab, Germany) transfection reagent. Following this, medium was exchanged with fresh growth medium $3 \mathrm{~h}$ post transfection. No osteogenic media was used in any experiment. Same cell densities and transfection procedures were used for all tested cells including rADSCs. Applied amounts and ratios of DNA and transfection reagent are based on previously performed optimisation screenings aiming for highest transfection efficiency and low toxicity (data provided in the supplementary material). Data sets were normalised with regard to transfection performed by Metridia luciferase reporter vector.

\section{Alkaline phosphatase assay}

Cells transfected with the indicated BMP-2 plasmid were lysed with $100 \mu \mathrm{L}$ lysis buffer consisting of alkaline phosphatase (ALP) buffer (0.5 M 2-Amino-2-Methyl1-Propanol, 2 mM magnesium chloride, $\mathrm{pH}$ 10.3) containing $0.5 \%$ Triton X-100 and incubated for $1 \mathrm{~h}$ at room temperature. Enzymatic activity was quantified in supernatants after centrifugation by adding $20 \mathrm{mM}$ p-nitrophenylphosphate in $50 \mu \mathrm{L}$ ALP buffer as substrate. The reaction was stopped after $20 \mathrm{~min}$ with $50 \mu \mathrm{L}$ of $0.2 \mathrm{M} \mathrm{NaOH}$. The conversion of p-nitrophenylphosphate to p-nitrophenol by ALP was quantified by its absorbance at $405 \mathrm{~nm}$. Depicted ALP activities are referred to nmol of p-nitrophenol liberated per minute.

Variations of time points for ALP quantification using different cell types were based on previously observed distinct differentiation kinetics. Therefore, different starting points of ALP quantification were chosen, according to the cell type's specific differentiation dynamic. ALP activity was measured $8 \mathrm{~d}(\mathrm{C} 2 \mathrm{C} 12), 14 \mathrm{~d}(\mathrm{C} 3 \mathrm{H} / 10 \mathrm{~T} 1 / 2)$ and $21 \mathrm{~d}$ (rADSCs) post transfection.

\section{Cell viability assay}

Cytotoxicity of plasmids in combination with the transfection reagent was evaluated by (3- (4,5-dimethylthiazol-2-yl)5-(3-carboxymethoxyphenyl)-2-(4-sulfophenyl)-2Htetrazolium), MTS assay (Promega, Madison, USA). $\mathrm{C} 3 \mathrm{H} / \mathrm{T} 101 / 2$ cells $\left(0.25 \times 10^{6} / \mathrm{cm}^{2}\right)$ in $1 \mathrm{~mL}$ of DMEM high glucose supplemented with $10 \%$ FCS were seeded in 24-well plates and transfected with indicated plasmids $(1 \mu \mathrm{g})$. Control was performed by incubating with $0.9 \%$ Triton X-100. After $24 \mathrm{~h}$, cells were washed with $1 \times$ PBS and $5 \mathrm{mg} / \mathrm{mL}$ MTS reagent in $1 \times \operatorname{PBS}(50 \mu \mathrm{L} /$ well $)$ and $100 \mu \mathrm{L}$ fresh medium was added. After $1 \mathrm{~h}$ of incubation at $37^{\circ} \mathrm{C}$, the absorbance at $490 \mathrm{~nm}$ was determined with a plate reader (POLARstar Omega, BMG LABTECH, Austria) (Data Analysis Software: MARS 2.30 R2).

\section{Alizarin red staining}

rADSCs transfected with the indicated BMP-2 plasmid were washed four weeks post transfection and subsequently fixed with $70 \%$ ethanol at $-20^{\circ} \mathrm{C}$ for $1 \mathrm{~h}$. Subsequent staining of calcium deposits was performed by incubation of cells with filtered $2 \%$ Alizarin Red solution (Sigma Aldrich, UK) ( $\mathrm{pH} \mathrm{4.2)} \mathrm{for} 10 \mathrm{~min}$. Absorbance of the centrifuged supernatant was determined at $405 \mathrm{~nm}$ with a plate reader (POLARstar Omega, BMG LABTECH, Austria) (Data Analysis Software: MARS 2.30 R2).

\section{Real time quantification}

All cell types used in this study were harvested and total Ribonucleic acid (RNA) was extracted using Trifast reagent (Peqlab, Germany). RNA concentrations were determined using a Hitachi U-5100 photometer (Metrohm 
$\mathrm{C} 2 \mathrm{C} 12$

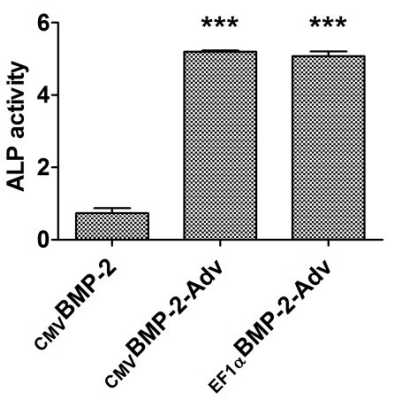

$\mathrm{C} 3 \mathrm{H} / 10 \mathrm{~T} 1 / 2$

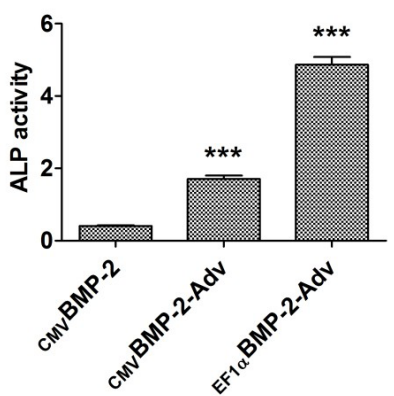

rADSC

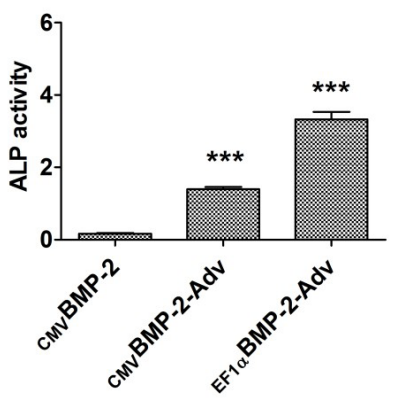

Viability (C3H/10T1/2)

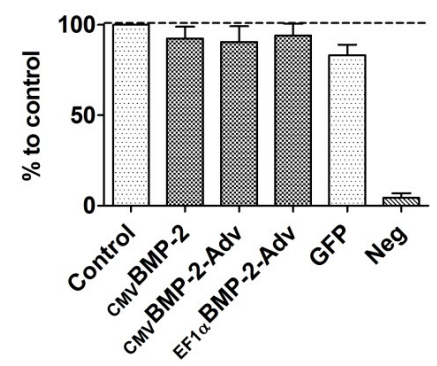

Fig. 2. Comparison of osteogenic differentiation of target cells induced by various vector constructs expressing bone morphogenetic protein 2 (BMP-2). Cells were transfected with either pVax1-BMP-2, pVax1-BMP-2-Advanced or pEF1 $\alpha$-BMP-2-Advanced plasmid $(1 \mu \mathrm{g} / \mathrm{mL})$, respectively. Quantification of induced ALP activity was measured after $8 \mathrm{~d}(\mathrm{C} 2 \mathrm{C} 12), 14 \mathrm{~d}(\mathrm{C} 3 \mathrm{H} / 10 \mathrm{~T} 1 / 2)$ and $21 \mathrm{~d}$ (rADSCs) post transfection showed several fold increase compared to conventional the BMP-2 vector. Additionally, pluripotent cell types showed increased osteogenic differentiation when transfected with the improved BMP-2 cassette under the influence of the EF1 $\alpha$ promoter compared to same BMP-2 cassette under the influence of the CMV promoter. Viability assay was performed in C3H/10T1/2 cells $24 \mathrm{~h}$ post transfection using untransfected cells as control. Transfection control was performed using pMax-GFP plasmid (Lonza/Amaxa, USA. Averaged data are presented as means \pm SD determined with four replicates, experiment was performed twice, $p<0.001$ ).

Inula $\mathrm{GmBH}$, Austria) and the complementary DNA (cDNA) was synthesised from the total RNA ( $2 \mu \mathrm{g})$ using a EasyScript ${ }^{\mathrm{TM}}$ cDNA Synthesis Kit (abmGood, Canada). Subsequently, the cDNA was added to real-time PCR mix using a KAPA SYBR Fast Universal (Peqlab, Germany). Each real-time PCR reaction consisted of $4 \mu \mathrm{L}$ of diluted RT product (40 ng), $10 \mu \mathrm{L}$ KAPA SYBR Fast Universal and specific primer pairs $(250 \mathrm{nM})$ in a total volume of $20 \mu \mathrm{L}$. The reactions were performed on a C1000 / CFX96 (Biorad, Germany) cycler using a 3 step protocol. The fold change in the mRNA levels of each gene was calculated using samples $\left(2^{\wedge}-(\mathrm{dCt})\right)$ divided by mean $\left(2^{\wedge}-(\mathrm{dCt})\right)$ of control group. The housekeeping gene glyceraldehyde 3-phosphate dehydrogenase (GAPDH) served for normalisation. All PCR primers were synthesised by Microsynth (Switzerland).

\section{Metridia luciferase assay}

$50 \mu \mathrm{L}$ of supernatant of transfected cells were removed at indicated time points for subsequent quantification of the secreted Metridia luciferase (Metridia longa) using coelenterazine substrate (NanoLight Technology, USA) using a Polar Star Omega Luminometer (BMG Labtech, Germany).

\section{Enzyme-linked immunosorbent assay}

Enzyme-linked immunosorbent assay (ELISA) was performed according to the DuoSet ELISA development system (R\&D Systems, USA). Mouse anti-human capture antibodies were used on supernatants collected from $\mathrm{CHO}$ cells $5 \mathrm{~d}$ post transfection with various BMP-2 gene containing constructs (Fig. 4).

\section{Statistical analysis}

Averaged data is presented as means \pm SD. Data sets were tested for gaussian distribution using KolmogorovSmirnov test (with Dallal-Wilkinson-Lillie for $p$ value).
Subsequent comparison between multiple data groups was performed by one-way ANOVA followed by Tukey posttest analysis. All statistical analyses were performed using GraphPad Prism 5 software. Differences were considered significant at $p<0.05$.

\section{Results}

Enhanced expression and osteogenic differentiation of various cell types mediated by improved BMP-2 gene sequence

BMP-2 gene cassette was modified using codon optimisation and by inserting a highly truncated artificial intron into the coding sequence (BMP-2-Advanced). Induction of osteogenic differentiation mediated by different BMP-2 gene constructs was compared by ALP assay measurement. Overall, comparison showed several fold increase in ALP activity in different target cells mediated by optimised BMP-2 gene (BMP-2-Advanced) compared to conventional BMP-2 gene. In more detail, transfection of $\mathrm{C} 2 \mathrm{C} 12$ myoblast cell line with plasmid containing the BMP-2-Advanced cassette under the influence of either CMV or EF1 $\alpha$ promoter showed over five-fold increase in ALP activity compared to the plasmid containing conventional BMP-2 gene (Fig. 2). Cell transfection with plasmids harbouring the improved BMP2 cassette triggered several fold higher ALP activities for pluripotent $\mathrm{C} 3 \mathrm{H} / 10 \mathrm{~T} 1 / 2$ and $\mathrm{rADSCs}$. Viability assay was performed in $\mathrm{C} 3 \mathrm{H} / 10 \mathrm{~T} 1 / 2$ cells $24 \mathrm{~h}$ post transfection and showed no significant toxic effects of transfection method in combination with applied plasmids compared to cells transfected with GFP plasmid or to untransfected control (Fig. 2). Furthermore, rADSCs transfected with BMP-2Advanced gene under the control of EF $1 \alpha$ promoter showed higher ALP activities in these cells compared to the CMV promoter construct. Mineralisation assay based on alizarin 
red staining underlined the observations of osteogenic differentiation of the various tested target cells previously quantified by ALP assay (Fig. 2). For further analysis, a kinetic experiment was conducted to obtain information about duration of gene expression mediated by different promoters. Interestingly, quantification of secreted BMP-2 revealed constant expression of protein induced by both tested promoters over a period of $8 \mathrm{~d}$. In conclusion, cell transfection with the improved BMP-2 gene cassette showed a significantly higher activity in all tested cell types compared to the conventional BMP-2 gene, regardless of used cell and promoter type.

A similar phenotype was observed after verification of osteogenic differentiation in transfected cells by quantitative real time analysis using bone specific markers such as Osteocalcin, Runx2, Osteopontin (Fig. 4). Again, advanced BMP-2 vector constructs showed significantly higher gene expression activity of osteogenic markers in all tested cell types compared to the native BMP-2 gene. Here too, an increased osteogenic differentiation potential of rADSCs induced by the BMP-2-Advanced cassette under the control of the EF1 $\alpha$ promoter was observed compared to the CMV promoter construct.

In order to directly link observed enhanced osteogenic differentiation of target cells to the amount of BMP-2 secretion, secretome of various transfected cell types was examined in parallel. Quantification of secreted BMP-2 protein $5 \mathrm{~d}$ post transfection revealed a linear relation to the measured ALP activity and therefore the stage of overall osteogenic differentiation of transfected target cells. Improved BMP-2 gene showed several fold better BMP-2 secretion than the native BMP-2 gene, and here too, EF $1 \alpha$ promoter displayed significantly higher activity in rADSCs than its CMV counterpart (Fig. 5).

Additionally, in order to quantify the absolute BMP-2 secretion, candidate plasmids were also transfected into $\mathrm{CHO}$ cells. Due to the lack of BMP receptors in $\mathrm{CHO}$ cells, auto- and paracrine re-uptake of secreted BMP-2 was circumvented and absolute protein secretion was determined. CHO cells transfected with the improved BMP-2 gene plasmid showed several fold higher BMP-2 secretion compared to conventional BMP-2 gene (Fig. 5). Interestingly, the EF1 $\alpha$ promoter construct again showed significantly better activity compared to the CMV promoter plasmid, a phenomenon, which was previously observed only in rADSCs. Finally and surprisingly, an $8 \mathrm{~d}$ experiment in $\mathrm{C} 3 \mathrm{H} / 10 \mathrm{~T} 1 / 2$ cells covering BMP-2 expression kinetics showed no significant differences.

\section{Comparison of various protein secretion signals showed superior potency of native protein secretion signal of BMP-2}

As final part of this work, different secretion signals were tested for possible exchange of the secretion signal of BMP-2 aiming for increase in protein secretion levels. Amongst the candidates, signals derived from inhibitory proteins (Noggin, Chordin, Gremlin-1) as well as from activator proteins (Osteopontin, BMP-6, BMP-7) expressed during osteogenic differentiation were included in the experiments.

\section{Mineralisation of rADSC}

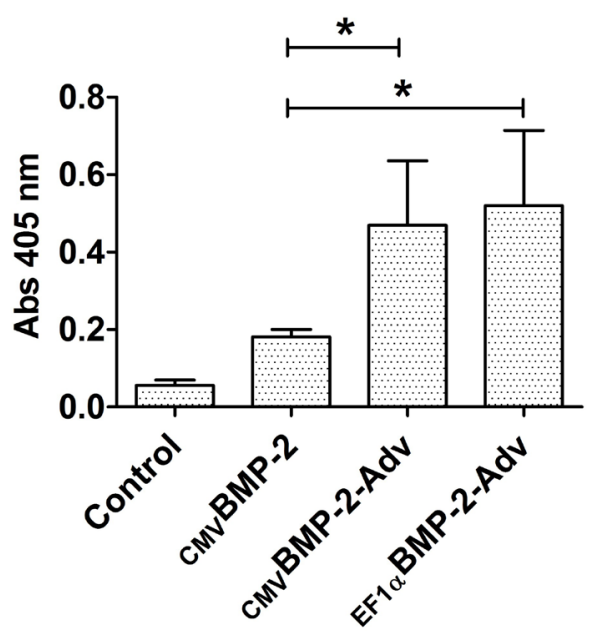

Fig. 3. Quantification of mineralisation of rADSCs after transfection with various vector constructs expressing bone morphogenetic protein 2 (BMP-2). rADSCswere transfected with either $\mathrm{pVax}$ 1-BMP-2, pVax1-BMP-2Advanced or pEF1 $\alpha$-BMP-2-Advanced plasmid ( $1 \mu \mathrm{g} /$ $\mathrm{mL}$ ), respectively. Additionally, untransfected cells served as reference (control). Alizarin red staining was performed four weeks post transfection. Cells transfected with enhanced BMP-2 cassette showed higher induction of mineralisation compared to cells transfected with conventional BMP-2 plasmid. Averaged data are presented as means $\pm \mathrm{SD}$, determined with four replicates, $p<0.001)$.

As a first step, the native secretion signal of Metridia luciferase was replaced with the secretion signal of the selected candidates. Subsequently, C2C12 cells were transfected with particular vector constructs and secreted Metridia luciferase was measured after $3 \mathrm{~d}$ (Fig. 6A). Quantification by Metridia luciferase assay, normalised with regard to transfection efficiency, revealed that the secretion signal sequence of BMP-2 as well as the signal sequences of all selected inhibitory factors of the osteogenic pathway (Noggin, Chordin, Gremlin-1) showed highest potential in mediating protein secretion in $\mathrm{C} 2 \mathrm{C} 12$ cells, whereas in contrast the secretion signal derived from BMP-7 displayed relatively weak potency.

Furthermore, a number of selected secretion signals were transferred to BMP-2 gene and exchanged with its original secretion signal (Fig. 6B). Additionally, further signals derived from different organisms were chosen in order to test for their potency to mediate BMP-2 secretion, amongst them, signals derived from cholera enterotoxin A subunit and viral interleukin-10 protein. In general, the selected secretion signals showed comparable potency to mediate secretion of BMP-2 as well as for Metridia luciferase reporter. One exception included the signal sequence of Trypsin-1, which was unable to retain same potency as previously displayed for the Metridia luciferase reporter. The signal sequence derived from BMP-7 protein was too weak to maintain sufficient BMP- 
Osteocalcin
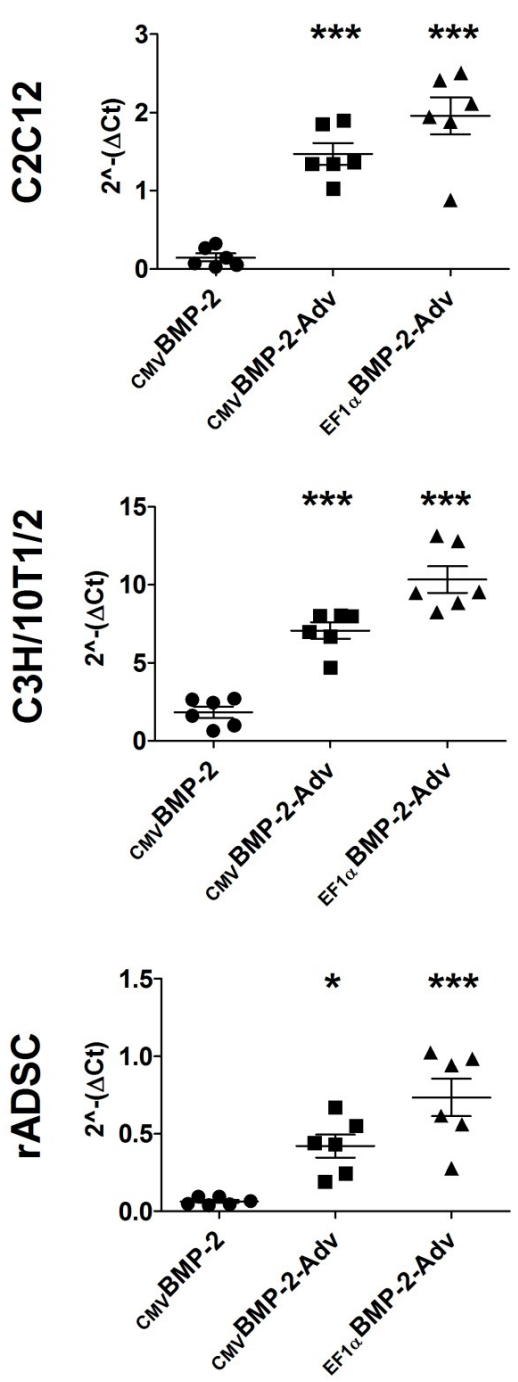

Runx2
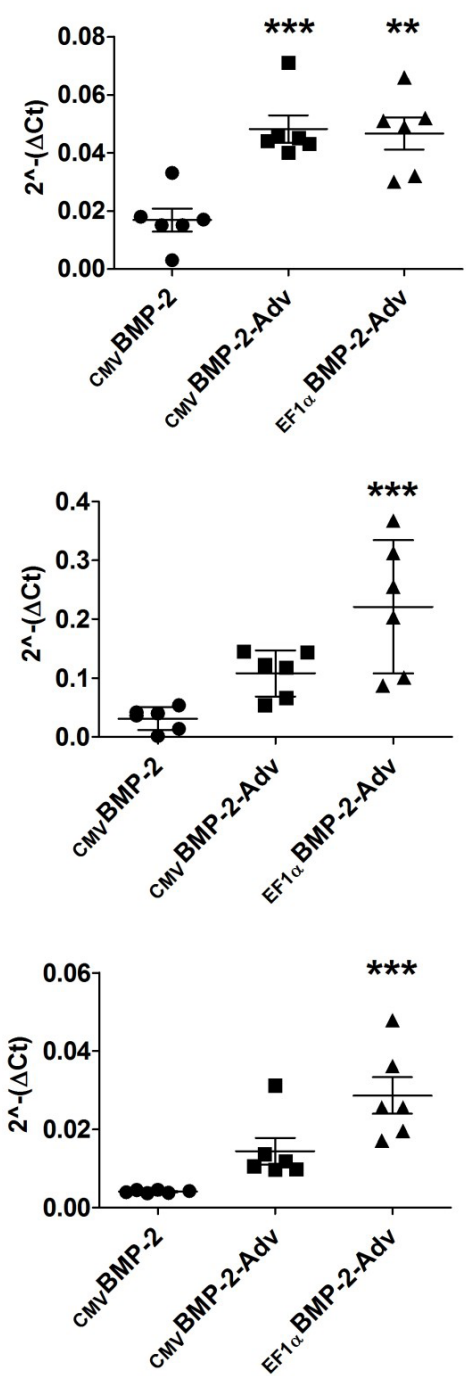

Osteopontin
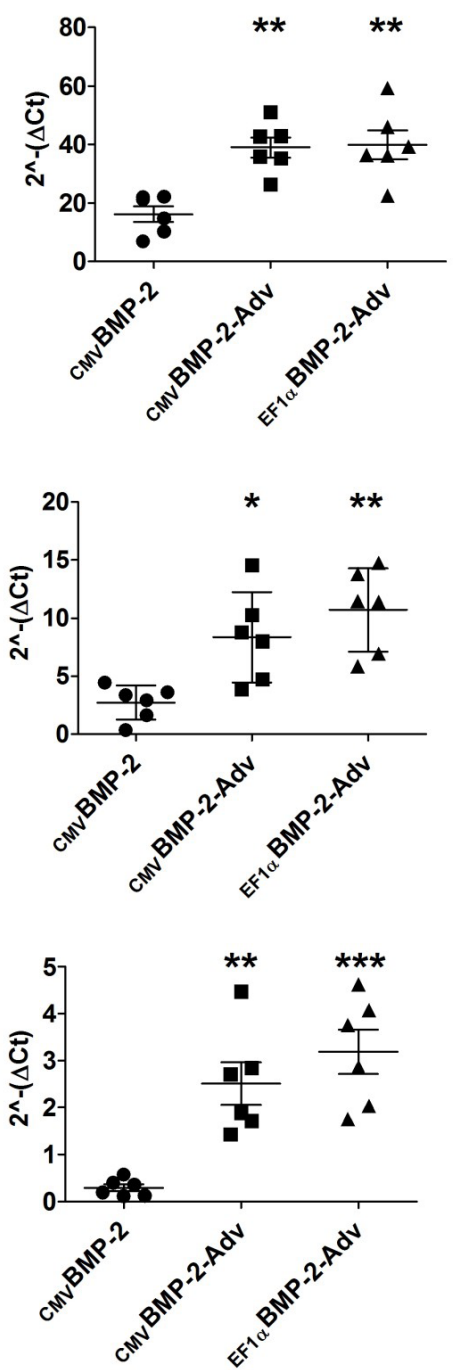

Fig. 4. Quantitative real time analysis in different cell lines after transfection with various vector constructs expressing bone morphogenetic protein 2 (BMP-2). Cells were transfected with either pVax1-BMP-2, pVax1-BMP-2-Advanced or pEF1 $\alpha$-BMP-2-Advanced plasmid $(1 \mu \mathrm{g} / \mathrm{mL})$, respectively. Quantification of osteogenic marker genes by quantitative real time analysis was performed $8 \mathrm{~d}(\mathrm{C} 2 \mathrm{C} 12), 14 \mathrm{~d}(\mathrm{C} 3 \mathrm{H} / 10 \mathrm{~T} 1 / 2)$ and $21 \mathrm{~d}(\mathrm{rADSCs})$ post transfection. All osteogenic marker genes showed several fold increase compared to cells transfected with conventional BMP-2 vector. Additionally, for pluripotent cell types, transfection with advanced BMP-2 gene under the influence of the EF1 $\alpha$ promoter showed higher expression of osteogenic marker genes compared to same cassette with CMV promoter, respectively. Averaged data are presented as means \pm SD determined with four replicates, experiment was performed twice, $p<0.001$ ).

2 secretion in order to induce osteogenic differentiation of $\mathrm{C} 2 \mathrm{C} 12$ precursor cells. In summary, the original secretion sequences of human BMP-2 mediated superior and very reliable protein secretion of either Metridia luciferase reporter or BMP-2 gene, respectively. None of the substituted secretion signals showed significant improvement in protein secretion compared to secretion mediated by native BMP-2 signal.

Modifications of the BMP-2 secretion signals resulted in a decreased potency

Further attempts to improve the secretion sequence of BMP-2, either by insertion of additional hydrophobic amino acids, or by addition of positively charged $\mathrm{N}$-terminal amino acids, led to a decreased protein secretion capacity. Only an exchange of the terminal cleavage site of the BMP-2 secretion signal (mB2a) showed significant improvement of potency compared to the original BMP-2 secretion signal.

Some attempts to improve another secretion signal derived from Gaussia luciferase, which was previously classified as a potent secretion signal, caused an increase in the secretion levels comparable to protein secretion levels mediated by the native BMP-2 secretion signal (Fig. 7). Especially the insertion of additional hydrophobic amino acids at the end of the hydrophobic core led to a 

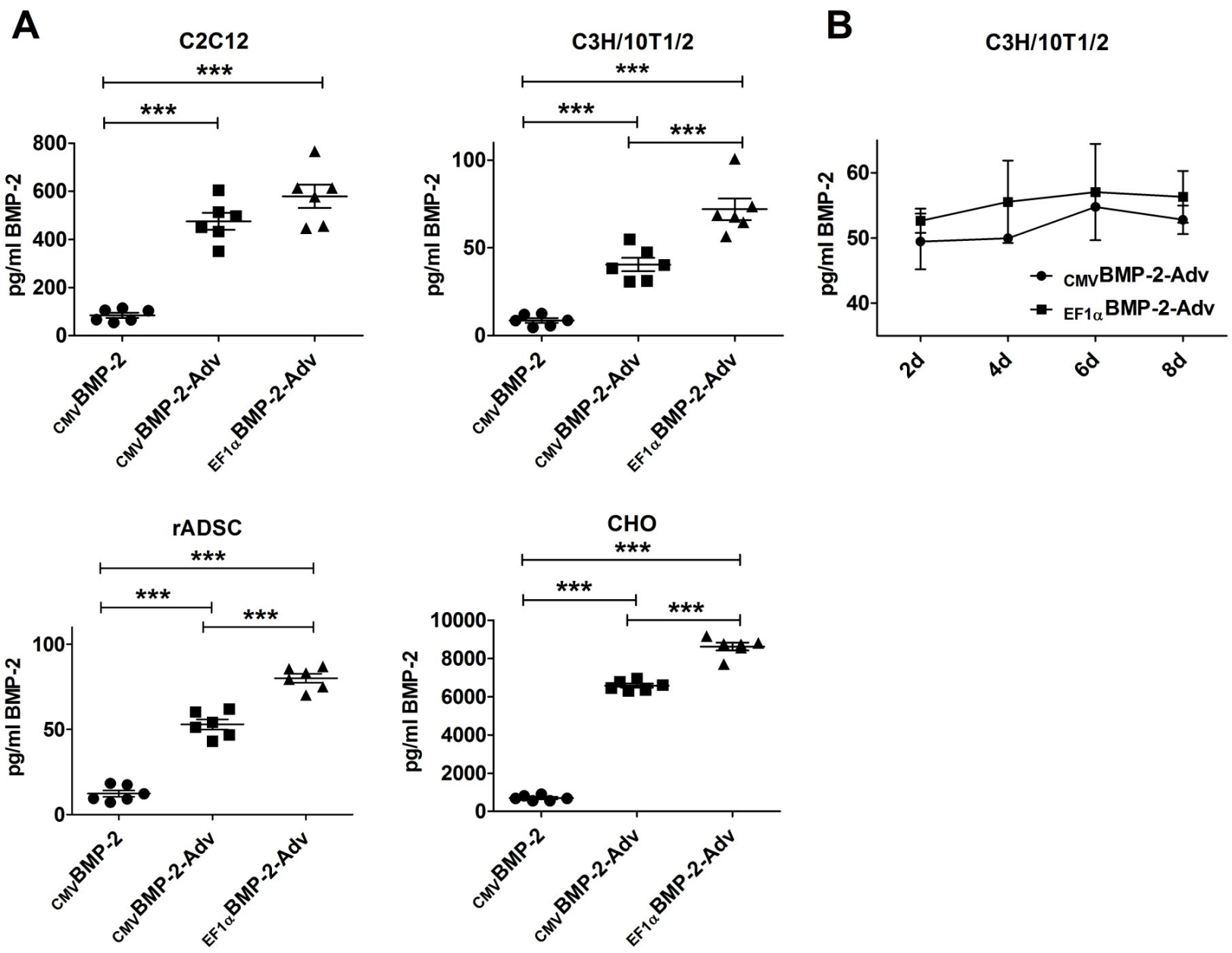

Fig. 5. Comparison of bone morphogenetic protein 2 (BMP-2) expression rate by ELISA analysis in different cell lines after transfection with various BMP-2 vector constructs Various cell types were transfected with either $\mathrm{pVax}$ 1BMP-2, pVax1-BMP-2-Advanced or pEF1 $\alpha$-BMP-2-Advanced plasmid (1 $\mu \mathrm{g} / \mathrm{mL})$, respectively. Quantification of secreted BMP-2 was determined by ELISA either $5 \mathrm{~d}$ post transfection (A), or every second day over a time period of $8 \mathrm{~d}(\mathbf{B})$. Averaged data is presented as means \pm SD determined with six replicates, experiment was performed twice, $p<0.001$ (A). Kinetic experiment $(\mathbf{B})$ was performed once with three replicates.

significant increase in potency compared to the native signal. Altogether, modifications on secretion signals resulted in either a slight improvement or complete loss of potency.

Additional experiments on protein secretion kinetics were performed in order to observe potential protein secretion dynamics within the first $3 \mathrm{~d}$ post transfection in $\mathrm{CHO}$ cells. Obtained data showed a constant protein secretion induced by all secretion signals except Trypsin-1 signal. Additionally, the data underlined previously evaluated high potencies of the secretion signals derived from BMP-2 protein, as well as its modified version $(\mathrm{mB} 2 \mathrm{a})$ and the artificially designed signal (Z) (Fig. 8). Interestingly, in contrast to other secretion signals, Metridia luciferase protein equipped with the secretion signal of human GDNF already showed a secretion stop after $24 \mathrm{~h}$. Subsequent toxicity assay showed no difference in viability of these cells compared to cells transfected with other signal sequences.

\section{Discussion}

Due to the fact that low gene delivery and subsequent low expression of the introduced genes is given (Glover et al., 2005), the application of non-viral gene transfer has been ignored for a long time. Nevertheless, due to its low immunotoxicity, non-viral vectors have regained significant attention in the past years. Advances in efficiency, specificity, duration of gene expression and safety led to a rising number of non-viral vector products entering clinical trials. However, there is still plenty of room for improvement of currently available non-viral vectors regarding expression rate and duration (Al-Dosari and Gao, 2009; Kay, 2011; Mingozzi and High, 2011; Wang et al., 2013). To promote further development of non-viral gene delivery approaches, non-viral expression systems were designed and tested for bone tissue engineering and regeneration. The described strategies can be transferred to any other gene expression system to increase specific gene expression. 


\section{Signal peptide potential}

A

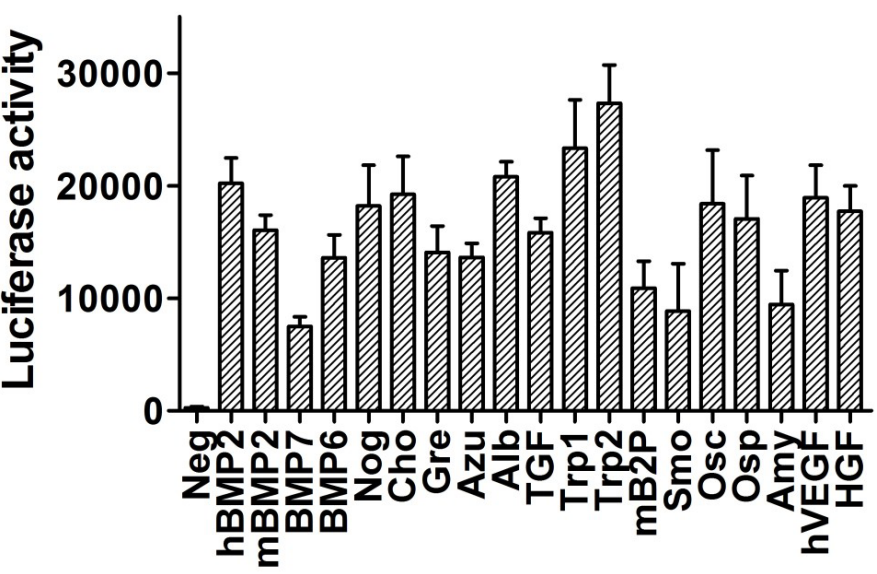

ssLuciferase
B

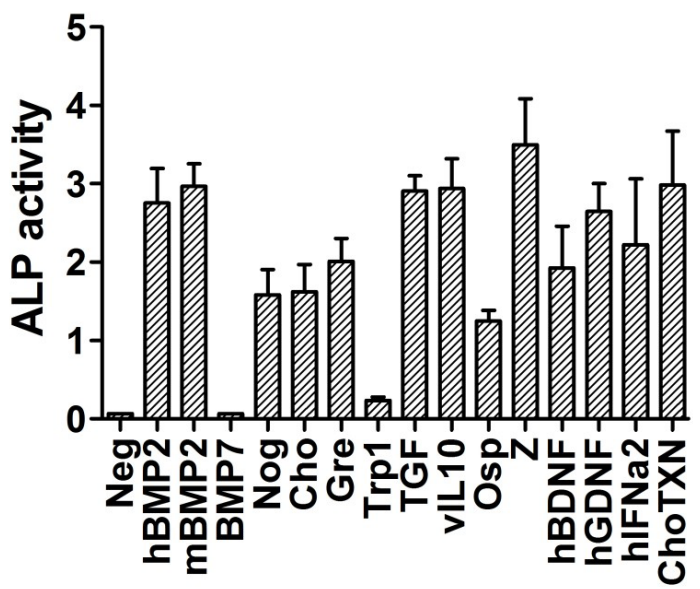

Fig. 6. Selected protein secretion signals were tested for their ability to drive protein secretion in $\mathrm{C} 2 \mathrm{C} 12$ cells. The native secretion signal of Metridia luciferase was replaced with the respective secretion signal of the selected candidates (Table 2). C2C12 cells were transfected with the particular vector constructs and secreted Metridia luciferase was measured 3 d post transfection (A). Secretion signal screen was translated into an osteogenic system. The native secretion signal of human BMP-2 gene was replaced with the respective secretion signal of the selected candidates (Table 2). C2C12 cells were transfected with the particular vector constructs and ALP activity was measured $6 \mathrm{~d}$ post transfection (B). None of the substituted secretion signals showed significant improvement in protein secretion compared to secretion mediated by native BMP-2 signal. Averaged data are presented as means \pm SD determined with six replicates).

Neg: without secretion signal, BMP: Bone morphogenetic protein, Nog: Noggin, Cho: Chordin, Gre: Gremlin-1, Azu: Azurocidin-1, Alb: Albumin, TGF: Transforming growth factor beta, Trp1: Trypsin-1, Trp2: Trypsin-2, Smo: SPARC related modular calcium binding 1, Osc: Osteocalcin, Osp: Osteopontin, Amy: Amyloid beta, VEGF: Vascular Endothelial Growth Factor A, HGF: Hepatocyte growth factor, vIL10: Viral Interleukin-10, Z: in silico designed, BDNF: Brain-derived neurotrophic factor, GDNF: Glial cell line-derived neurotrophic factor, IFNa2: Interferon alpha 2, ChoTXN: Cholera enterotoxin A subunit, SS: secretion signal.

Several studies have successfully exploited codon optimisation to increase yield in eukaryotic cells for in vitro production of recombinant proteins (interleukin $2(\mathrm{Ou}$ et al., 2014), coagulation factor VIII (Ward et al., 2011)), vaccination (Frelin et al., 2004; Ko et al., 2005), and gene replacement therapy such as microdystrophin (Foster et al., 2008) and PhiC31 recombinase (Raymond and Soriano, 2007). However, codon optimisation on growth factor genes for application in tissue regeneration has great potential, but has mostly been unexploited yet. Concerning BMPs, a single recombinant protein production study exists describing a five-fold enhanced expression of BMP4 in Pichia pastoris (Huang et al., 2014), underlining untouched opportunities improving the outcome for gene therapeutical approaches. In our case, a several fold increase in osteogenic response in vitro was achieved by modifying the BMP-2 gene sequence as mentioned above, which is crucial when low transfection efficiencies have to be compensated, predominantly occurring in applications in vivo. Codon optimisation of the BMP-2 gene to adjust codon usage frequency within the mammalian organism as well as the addition of an artificial short intron element (intron) derived from alpha globin gene, resulted in several-fold higher osteogenic response of target cells after transfection, indicating a higher expression rate of the modified BMP-2 sequence compared to the unmodified gene. These higher production rates were verified by quantification of secreted BMP-2 levels produced by $\mathrm{CHO}$ cells. The positive effect of codon optimisation on gene expression levels is not exclusively explainable by codon usage and particular tRNA levels of the respective organisms. Alteration of nucleotide sequence during codon optimisation process would eradicate potential binding sites of endogenous regulatory and transcription factors which could hinder efficient transcription.

Apart from codon optimisation, the major reason for enhanced gene expression in our study is assumed to be based on the subsequent insertion of an artificial intron into the coding region of the gene. Underlying mechanisms for increased expression are not yet fully understood. One explanation is that introns contain sequence motifs that stimulate the elongation complex during transcription. This theory, however, does not apply to our introduced highly minimised intron, due to its randomly designed 


\section{Modification of native secretion signal}
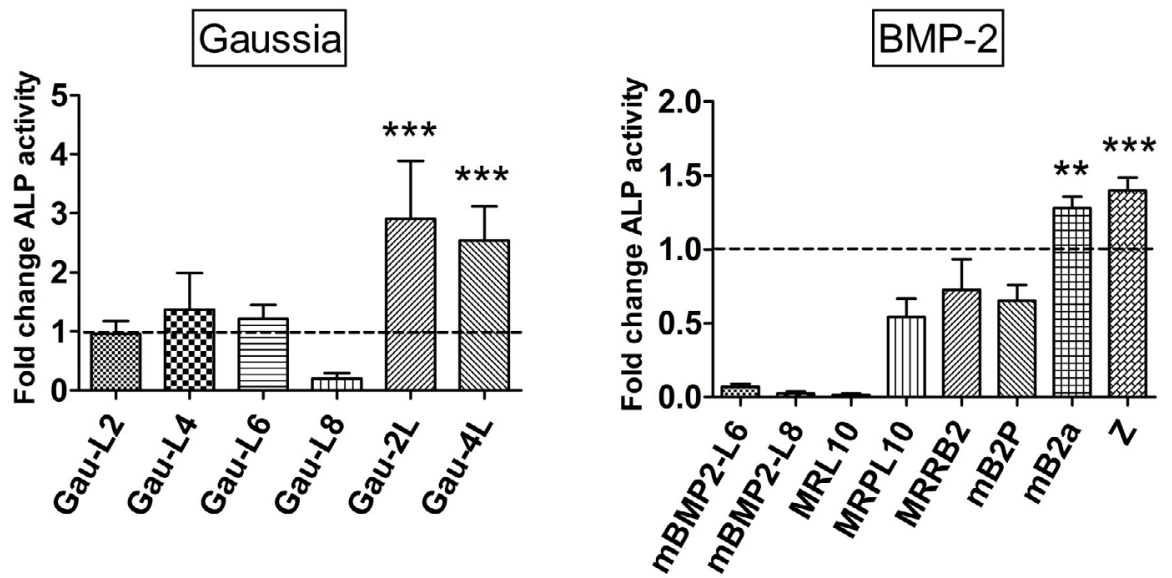

Fig. 7. Modification of protein secretion signals of Gaussia luciferase and human bone morphogenetic protein 2 (BMP-2) gene. The native secretion signal of human BMP-2 was replaced with the respective secretion signal derived from modifications of the signals of Gaussia luciferase and human BMP-2 gene. C2C12 cells were transfected with the particular vector constructs and ALP activity was measured $6 \mathrm{~d}$ post transfection in order to test the efficiency of the modified signals to drive BMP-2 secretion. Averaged data is presented as means \pm SD determined with six replicates, experiment was performed twice, $\mathrm{p}<0.001$.

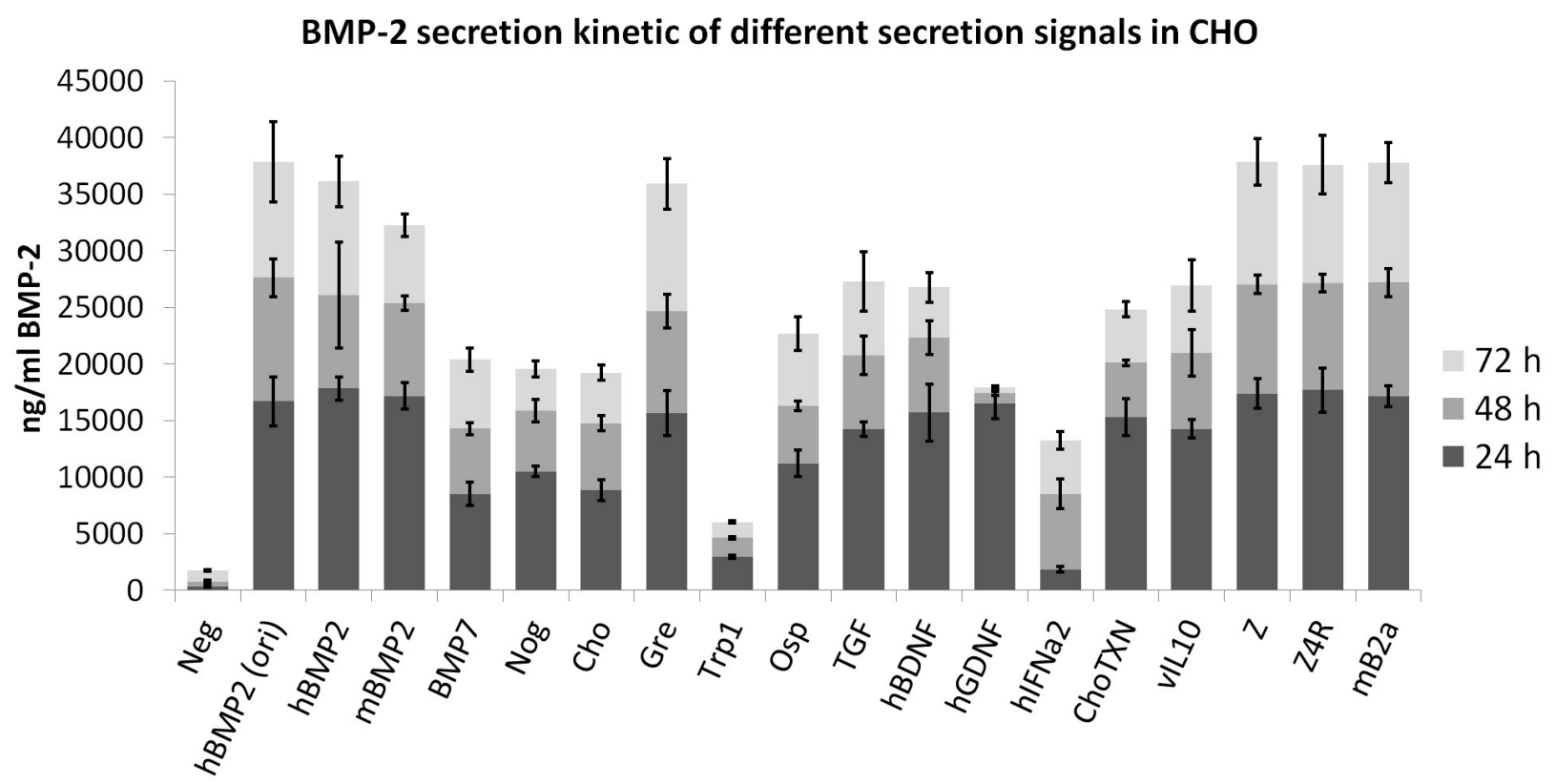

Fig. 8. Selected protein secretion signals were tested for their ability to drive protein secretion in CHO cells. The native secretion signal of BMP-2 gene was replaced with the respective secretion signal of the selected candidates. $\mathrm{CHO}$ cells were transfected with the particular vector constructs and secreted BMP-2 protein was measured $24 \mathrm{~h}, 48 \mathrm{~h}$ and $72 \mathrm{~h}$ post transfection (A). In order to evaluate net secretion, culture medium was replaced with fresh medium $24 \mathrm{~h}$ prior taking aliquots for subsequent BMP-2 quantification by ELISA. Averaged data are presented as means \pm SD determined with six replicates.

Neg: without secretion signal, BMP: Bone morphogenetic protein, Ori: original unmodified (without insertion of restriction sites), Nog: Noggin, Cho: Chordin, Gre: Gremlin-1, TGF: Tissue growth factor beta, Trp1: Trypsin-1, Osp: Osteopontin, vIL10: viral Interleukin-10, Z, Z4R: in silico designed, mB2a: modified bone morphogenetic protein 2, BDNF: Brain-derived neurotrophic factor, GDNF: Glial cell line-derived neurotrophic factor, IFNa2: Interferon alpha 2, ChoTXN: Cholera enterotoxin A subunit, SS: secretion signal. 
artificial sequence. A more likely explanation is, given that transcription and splicing procedures are executed simultaneously, splicing factors improve transcription by reducing transcription-associated genome instability (Moabbi et al., 2012; Niu and Yang, 2011; Rose, 2008).

With regards to regulatory elements, cells transfected with the BMP-2-Advanced gene under the control of EF $1 \alpha$ promoter showed higher expression activities compared to cells transfected with the CMV promoter construct. Also, when under the influence of the EF1 $\alpha$ promoter, increased osteogenic differentiation was observed in rADSCs. This is most likely caused either by enhanced BMP-2 expression activity or due to possible silencing of the CMV promoter. This active shut down of transcription is mediated by inhibitory factors or the lack of specific transcription factors essential for gene expression. rADSCs might have the (co)-factors necessary for full transcriptional activity of cellular promoters, such as the EF1 $\alpha$ promoter, which may operate more ubiquitously. A similar gene expression phenotype was observed previously by Chung et al. in transiently transfected mouse embryonic stem cells (Chung et al., 2002). The group showed that both the EF1 $\alpha$ and chicken $\beta$-actin promoter strongly triggered reporter gene expression while the viral CMV promoter was largely inactive but became active upon differentiation of the stem cells to neuronal precursor cells. Furthermore, observed results go in line with the results obtained by another study, underlining the susceptibility of the CMV promoter to specific cell types, among them mesenchymal stem cells (Qin et al., 2010). Interestingly, quantification of BMP-2 release in $\mathrm{C} 3 \mathrm{H} / 10 \mathrm{~T} 1 / 2$ cells over an $8 \mathrm{~d}$ period revealed no significant difference in gene expression kinetics of both promoters.

However, it has been demonstrated that the yield of recombinant proteins does not necessarily correlate with their mRNA levels (Barnes et al., 2004; Knappskog et al., 2007). Regarding the application of genes encoding for extracellular growth factors, inefficient protein secretion can be an additional bottleneck. Therefore, this study further focused on the identification of more potent signal sequences mediating increased protein secretion for gene therapeutic applications in bone tissue regeneration. Human BMP-2 was used as a standard growth factor candidate for osteogenic gene therapy (Bonadio et al., 1999; Einhorn, 2003; Johnson and Urist, 2000; Loozen et al., 2015; Osawa et al., 2009; Tepper and Mehrara, 2002). Various secretion signals as well as their modifications derived either from osteogenic factors or previously documented resources were compared amongst each other to mediate secretion of Metridia luciferase or human BMP-2 protein.

Compared to other protein secretion signals, the signal sequence of the BMP-2 gene showed superior ability to mediate secretion of either Metridia luciferase reporter protein or BMP-2. Interestingly, the secretion signal derived from BMP-7, a protein, which is used to form heterodimers with BMP-2 in equimolar ratios, displayed relatively weak potencies compared to the BMP-2 signal. Additional modifications of the BMP-2 signal sequence led to loss of potency in secretion when altering the length of the sequence rather than altering specific amino acids. Therefore, previously described observations of enhanced potency of a secretion signal by increasing the basicity and hydrophobicity of the amino acid composition (Zhang et al., 2005) are in contrast to our results obtained after modifications of the BMP-2 secretion signal. One of the few candidates which displayed a potency to mediate protein secretion comparable to, or higher than, the native BMP-2 signal sequence was a signal sequence designed in silico $(\mathrm{Z})$, consisting of a typical short basic region followed by a hydrophobic area combined with an in silico designed cleavage site. Finally, the secretion signal of Gaussia luciferase, which was previously shown to have high activity to mediate protein secretion (Knappskog et al., 2007), was only comparable to BMP-2 signal potency after additional modifications were performed at the hydrophobic domain. In conclusion, attempts to enhance secretion signal of BMP-2 were mostly unsuccessful due to the strength of the existing native signal. Nevertheless, based on the new insights the signal sequence of BMP2 is a promising candidate to increase protein secretion by replacing native sequences of other proteins of interest, such as growth factors in gene therapeutic or biotechnological approaches.

\section{Conclusion}

In this work, we have introduced modifications to BMP-2 expression systems in order to compensate for poor transfection efficiencies in non-viral gene transfer, successfully making these safe systems even more applicable for tissue engineering approaches. First, it was shown that codon optimisation of BMP-2 gene, as well as insertion of an intron, resulted in enhanced BMP2 expression and osteogenic differentiation in vitro. In rADSCs, the osteoinductive effect was further enhanced by replacement of the viral state of the art promoter (CMV) with a potent mammalian promoter $(\mathrm{EF} 1 \alpha)$. Finally, it was revealed that the native BMP-2 secretion signal shows high efficacy in mediating protein secretion. Therefore, this method, as well as the potent BMP-2 secretion sequence itself, offer additional options to consider in improving poor protein expression.

Altogether, data obtained from our study encourage us to further push investigations on transferring this approach to in vivo settings.

\section{Acknowledgements}

This work was funded by the EUROSTARS project 829449 UGen and Biodesign (FP7, 262948). We thank Eva Tögel for technical assistance.

\section{References}

Al-Dosari MS, Gao X (2009) Nonviral gene delivery: principle, limitations, and recent progress. AAPS J 11: 671-681.

Alt V, Donell ST, Chhabra A, Bentley A, Eicher A, Schnettler R (2009) A health economic analysis of the 
use of rhBMP-2 in Gustilo-Anderson grade III open tibial fractures for the UK, Germany, and France. Injury 40: 1269-1275.

Barnes LM, Bentley CM, Dickson AJ (2004) Molecular definition of predictive indicators of stable protein expression in recombinant NS0 myeloma cells. Biotechnol Bioeng 85: 115-121.

Bleiziffer O, Eriksson E, Yao F, Horch RE, Kneser U (2007) Gene transfer strategies in tissue engineering. J Cell Mol Med 11: 206-223.

Bonadio J, Smiley E, Patil P, Goldstein S (1999) Localized, direct plasmid gene delivery in vivo: prolonged therapy results in reproducible tissue regeneration. Nat Med 5: 753-759.

Cai H, Li Y, Zhang H, Feng F (2013) [Effects of gene design on recombinant protein expression: a review]. Sheng Wu Gong Cheng Xue Bao 29: 1201-1213.

Carragee EJ, Hurwitz EL, Weiner BK (2011) A critical review of recombinant human bone morphogenetic protein-2 trials in spinal surgery: emerging safety concerns and lessons learned. Spine J 11: 471-491.

Celeste AJ, Iannazzi JA, Taylor RC, Hewick RM, Rosen V, Wang EA, Wozney JM (1990) Identification of transforming growth factor beta family members present in bone-inductive protein purified from bovine bone. Proc Natl Acad Sci U S A 87: 9843-9847.

Chung S, Andersson T, Sonntag KC, Bjorklund L, Isacson O, Kim KS (2002) Analysis of different promoter systems for efficient transgene expression in mouse embryonic stem cell lines. Stem Cells 20: 139-145.

Einhorn TA (2003) Clinical applications of recombinant human BMPs: early experience and future development. J Bone Joint Surg Am 85-A Suppl 3: 82-88.

Fath S, Bauer AP, Liss M, Spriestersbach A, Maertens B, Hahn P, Ludwig C, Schafer F, Graf M, Wagner R (2011) Multiparameter RNA and codon optimization: a standardized tool to assess and enhance autologous mammalian gene expression. PLoS One 6: e17596.

Feichtinger GA, Hacobian A, Hofmann AT, Wassermann K, Zimmermann A, van Griensven M, Redl H (2014) Constitutive and inducible co-expression systems for non-viral osteoinductive gene therapy. Eur Cell Mater 27: 166-184.

Foster H, Sharp PS, Athanasopoulos T, Trollet C, Graham IR, Foster K, Wells DJ, Dickson G (2008) Codon and mRNA sequence optimization of microdystrophin transgenes improves expression and physiological outcome in dystrophic mdx mice following AAV2/8 gene transfer. Mol Ther 16: 1825-1832.

Frelin L, Ahlen G, Alheim M, Weiland O, Barnfield C, Liljestrom P, Sallberg M (2004) Codon optimization and mRNA amplification effectively enhances the immunogenicity of the hepatitis $\mathrm{C}$ virus nonstructural 3/4A gene. Gene Ther 11: 522-533.

Futatsumori-Sugai M, Tsumoto K (2010) Signal peptide design for improving recombinant protein secretion in the baculovirus expression vector system. Biochem Biophys Res Commun 391: 931-935.

Glassman SD, Gum JL, Crawford CH 3rd, Shields CB, Carreon LY (2011) Complications with recombinant human bone morphogenetic protein-2 in posterolateral spine fusion associated with a dural tear. Spine J 11: $522-$ 526.

Glover DJ, Lipps HJ, Jans DA (2005) Towards safe, non-viral therapeutic gene expression in humans. Nat Rev Genet 6: 299-310.

Huang Y, Zhen B, Lin Y, Cai Y, Lin Z, Deng C, Zhang $\mathrm{Y}$ (2014) Expression of codon optimized human bone morphogenetic protein 4 in Pichia pastoris. Biotechnol Appl Biochem 61: 175-183.

Johnson EE, Urist MR (2000) Human bone morphogenetic protein allografting for reconstruction of femoral nonunion. Clin Orthop Relat Res 371: 61-74.

Kay MA (2011) State-of-the-art gene-based therapies: the road ahead. Nat Rev Genet 12: 316-328.

Kempen DH, Creemers LB, Alblas J, Lu L, Verbout AJ, Yaszemski MJ, Dhert WJ (2010) Growth factor interactions in bone regeneration. Tissue Eng Part B Rev 16: 551-566.

Klatt S, Konthur Z (2012) Secretory signal peptide modification for optimized antibody-fragment expressionsecretion in Leishmania tarentolae. Microb Cell Fact 11: 97.

Knappskog S, Ravneberg H, Gjerdrum C, Trosse C, Stern B, Pryme IF (2007) The level of synthesis and secretion of Gaussia princeps luciferase in transfected $\mathrm{CHO}$ cells is heavily dependent on the choice of signal peptide. J Biotechnol 128: 705-715.

Ko HJ, Ko SY, Kim YJ, Lee EG, Cho SN, Kang CY (2005) Optimization of codon usage enhances the immunogenicity of a DNA vaccine encoding mycobacterial antigen Ag85B. Infect Immun 73: 5666-5674.

Kober L, Zehe C, Bode J (2013) Optimized signal peptides for the development of high expressing $\mathrm{CHO}$ cell lines. Biotechnol Bioeng 110: 1164-1173.

Koh JT, Zhao Z, Wang Z, Lewis IS, Krebsbach PH, Franceschi RT (2008) Combinatorial gene therapy with BMP2/7 enhances cranial bone regeneration. J Dent Res 87: 845-849.

Le Hir H, Nott A, Moore MJ (2003) How introns influence and enhance eukaryotic gene expression. Trends Biochem Sci 28: 215-220.

Loozen LD, van der Helm YJ, Oner FC, Dhert WJ, Kruyt MC, Alblas J (2015) Bone morphogenetic protein-2 nonviral gene therapy in a goat iliac crest model for bone formation. Tissue Eng Part A 21: 1672-1679.

Martin T, Parker SE, Hedstrom R, Le T, Hoffman SL, Norman J, Hobart P, Lew D (1999) Plasmid DNA malaria vaccine: the potential for genomic integration after intramuscular injection. Hum Gene Ther 10: 759-768.

Mingozzi F, High KA (2011) Therapeutic in vivo gene transfer for genetic disease using AAV: progress and challenges. Nat Rev Genet 12: 341-355.

Moabbi AM, Agarwal N, El Kaderi B, Ansari A (2012) Role for gene looping in intron-mediated enhancement of transcription. Proc Natl Acad Sci U S A 109: 8505-8510.

Niu DK, Yang YF (2011) Why eukaryotic cells use introns to enhance gene expression: splicing reduces transcription-associated mutagenesis by inhibiting topoisomerase I cutting activity. Biol Direct 6: 24 .

Osawa K, Okubo Y, Nakao K, Koyama N, Bessho K (2009) Osteoinduction by microbubble-enhanced 
transcutaneous sonoporation of human bone morphogenetic protein-2. J Gene Med 11: 633-641.

Ou KC, Wang CY, Liu KT, Chen YL, Chen YC, Lai MD, Yen MC (2014) Optimization protein productivity of human interleukin-2 through codon usage, gene copy number and intracellular tRNA concentration in $\mathrm{CHO}$ cells. Biochem Biophys Res Commun 454: 347-352.

Qin JY, Zhang L, Clift KL, Hulur I, Xiang AP, Ren BZ, Lahn BT (2010) Systematic comparison of constitutive promoters and the doxycycline-inducible promoter. PLoS One 5: e10611.

Raymond CS, Soriano P (2007) High-efficiency FLP and PhiC31 site-specific recombination in mammalian cells. PLoS One 2: e162.

Reddi AH (1998) Role of morphogenetic proteins in skeletal tissue engineering and regeneration. Nat Biotechnol 16: 247-252.

Rose AB (2008) Intron-mediated regulation of gene expression. Curr Top Microbiol Immunol 326: 277-290.

Sandhu H (2004) Spinal fusion using bone morphogenetic proteins. Orthopedics 27: 717-718.

Shimer AL, Oner FC, Vaccaro AR (2009) Spinal reconstruction and bone morphogenetic proteins: open questions. Injury 40 Suppl 3: S32-38.

Sood S, Gupta S, Mahendra A (2012) Gene therapy with growth factors for periodontal tissue engineering - a review. Med Oral Patol Oral Cir Bucal 17: e301-310.

Southwood LL, Frisbie DD, Kawcak CE, McIlwraith CW (2004) Delivery of growth factors using gene therapy to enhance bone healing. Vet Surg 33: 565-578.

Tepper OM, Mehrara BJ (2002) Gene therapy in plastic surgery. Plast Reconstr Surg 109: 716-734.

Wang W, Li W, Ma N, Steinhoff G (2013) Non-viral gene delivery methods. Curr Pharm Biotechnol 14: 46-60.

Ward NJ, Buckley SM, Waddington SN, Vandendriessche T, Chuah MK, Nathwani AC, McIntosh J, Tuddenham EG, Kinnon C, Thrasher AJ, McVey JH (2011) Codon optimization of human factor VIII cDNAs leads to high-level expression. Blood 117: 798-807.

Wen B, Deng Y, Guan J, Yan W, Wang Y, Tan W, Gao J (2011) Signal peptide replacements enhance expression and secretion of hepatitis $C$ virus envelope glycoproteins. Acta Biochim Biophys Sin (Shanghai) 43: 96-102.

Wozney JM, Rosen V (1998) Bone morphogenetic protein and bone morphogenetic protein gene family in bone formation and repair. Clin Orthop Relat Res 346: 26-37.

Zhang L, Leng Q, Mixson AJ (2005) Alteration in the IL-2 signal peptide affects secretion of proteins in vitro and in vivo. J Gene Med 7: 354-365.

\section{Discussion with Reviewers}

Reviewer I: What is the particular advantage of gene delivery when compared to recombinant protein delivery in this type of application?

Authors: Recombinant BMP-2 has a short half-life at the target site. Consequently, it requires delivery of up to $\mathrm{mg}$ dosages at once to provide a sufficient stimulus to induce osteogenic differentiation and bone formation. These supraphysiological local dosages lead to increased occurrence of protein diffusion and side effects. Gene therapy as a way to locally administer BMP2 can overcome the use of high protein doses due to the moderate but sustained release of protein. Since permanent expression of growth factors is undesirable in regenerative processes, non-viral transient and local gene expression is more suitable for this application.

An additional advantage of gene therapy is the increased biocompatibility of expressed BMP-2. The protein is produced de novo by host cells and not by xenogenous cells, e.g. chinese hamster ovary cells or yeast. This way, post-translational modifications such as host specific glycosylation patterns are more compatible with the target tissue.

Reviewer I: What are the potential risks associated with non-viral gene delivery, and how are they mitigated by proper plasmid design?

Authors: Although non-viral gene delivery is significantly safer compared to viral vector systems, occurrence of insertional mutagenesis can still occur. Regarding safety of plasmids, the FDA Center for Biologics Evaluation and Research (CBER) has listed some points to follow in the document, "Points to Consider on Plasmid DNA Vaccines for Preventive Infectious Diseases Indications" (Docket no. 96N-0400). In general, all sequences except the ones required for replication in E. coli and for expression of recombinant protein in mammalian cells should be removed. This reduces DNA sequences with possible homology to the human genome and minimises the possibility of chromosomal integration. Furthermore, the gene of interest sequence can be optimised without changing the final amino acid composition to further decrease random homology.

Safety of plasmids can further be increased by introduction of specific elements controlling gene of interest expression. Beside inducible promoters, such as Tetracycline/Doxycycline responsive expression, this can be achieved by introducing tissue specific promoters, thereby reducing unwanted gene expression in other tissues. Tissue specific gene expression can also be accomplished by insertion of target sequences for endogenous microRNAs. These miRNA target sequences within the plasmids expression cassette can be used to regulate transgene expression according to tissue, lineage and differentiation state of target cells. (Brown et al., 2007) have combined two miRNA target sites to restrict transgene expression to a specific cell type in the liver [1]. Therefore, miRNA-regulated vectors can also lead to safer and more effective therapeutic applications.

Another aspect to consider is toxicity of non-viral shuttle systems, such as polycations and cationic lipids. Although significantly less immunogenic compared to viral systems, toxicity (e.g. accumulation in the liver, interactions with blood components) is still a drawback. In general, DNA/carrier complexes have to expose an overall positive net charge in order to interact with negatively charged cell surface and promote endocytotic uptake. This charge can interact with other systemic components resulting in unwanted side effects. As a rule of thumb, the 
less the positive net charge, the safer the delivery system, but with respect to decreased transfection efficiency. To avoid the necessity of electrostatic contact, one alternative includes the introduction of gene transfer systems based on receptor/ligand interactions (e.g. transferrin).

Reviewer II: Isolation and cultivation of rADSC. The authors use epididymal fat to perform the isolation of mesenchymal stem cells. The authors also stated that the characterisation of isolated cells was performed by FACS for the standard markers: CD34, CD45, CD73, CD90, CD105 etc. Please provide the FACS characterisation of the isolated cells as supplementary material. This is important as it has been reported that ADSCs from epididymal fat differ substantially in terms of morphology and surface markers from the ones isolated from liposuction or abdominal fat tissue.

Authors: FACS characterisation data of isolated ADSCs is provided as supplementary material. rADSC specific (CD73, CD90, CD105) as well as haematopoietic markers as a negative control (CD14, CD34, CD45) were used to characterise the isolated cells according to (Dominici et al., 2006).

Reviewer II: Fig. 7 shows an ELISA quantification of BMP-2 after the native secretion signal was replaced with the secretion signal of a number of selected candidates. Do such modifications affect the ability of antibodies to bind BMP-2 with the same efficacy, compromising the reliability of the assay? Can the authors please comment on this?

Authors: During conventional protein secretion, the signal sequence of secretory proteins is immediately cleaved from the nascent (denatured) polypeptide by signal peptidase once it has been translocated into the membrane of the endoplasmic reticulum (ER). BMP-2 with replaced secretion signals is subject to the same secretion procedure. Therefore, all BMP-2 proteins, even when equipped with different secretion signals, consist of the same amino acid sequence and undergo same folding processes in equal conditions inside the ER. We therefore conclude that secreted BMP-2 proteins have identical conformation and hence are recognised and bound by antibodies with same affinities during ELISA.

\section{Additional References}

Brown BD, Gentner B, Cantore A, Colleoni S, Amendola M, Zingale A, Baccarini A, Lazzari G, Galli C, Naldini L (2007) Endogenous microRNA can be broadly exploited to regulate transgene expression according to tissue, lineage and differentiation state. Nat Biotechnol 25: $1457-1467$.

Dominici M, Le Blanc K, Müller I, Slaper-Cortenbach I, Marini F, Krause D, Deans R, Keating A, Prockop DJ, Horwitz E (2006) Minimal criteria for defining multipotent mesenchymal stromal cells. The International Society for Cellular Therapy position statement. Cytotherapy 8: 315 317.

Editor's Note: Scientific Editor in charge of the paper: Chris Evans. 